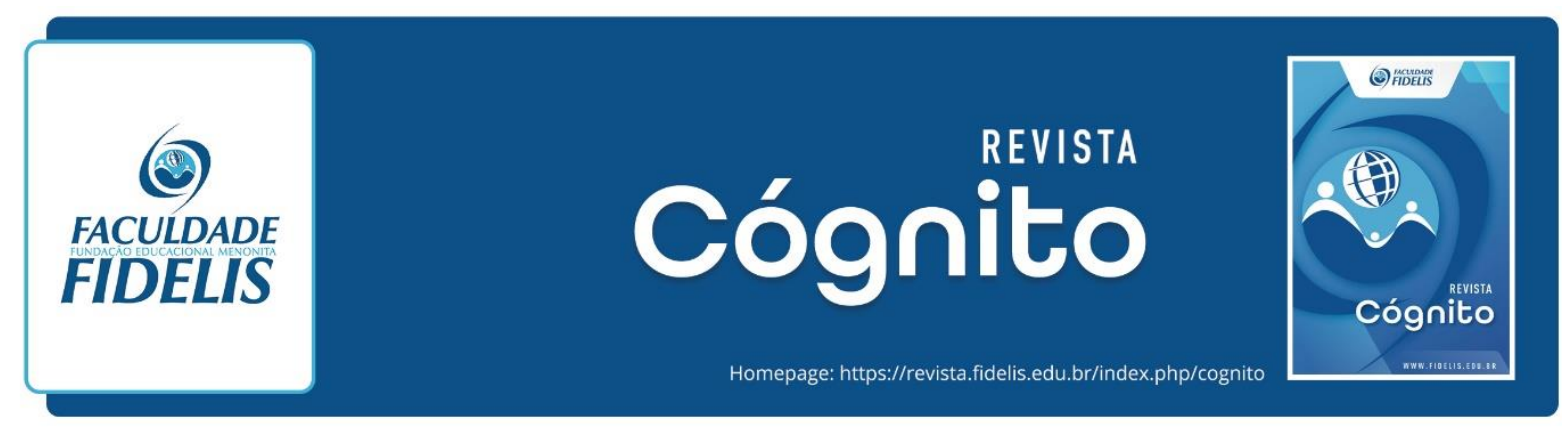

\title{
A IMPORTÂNCIA DA EMPATIA NO CUIDADO ESPIRITUAL
} THE IMPORTANCE OF EMPATHY IN SPIRITUAL CARE

Hartmut August ${ }^{1}$

Mariluce Emerim de Melo August ${ }^{2}$

\section{RESUMO:}

Um dos elementos fundamentais para a escuta e acolhimento das pessoas que buscam aconselhamento pastoral e precisam de cuidado espiritual é a empatia. O propósito desse estudo é descrever, a partir dos estudos de Edith Stein, a natureza da empatia e refletir sobre sua importância no cuidado espiritual. O valor de uma atitude empática da parte do conselheiro espiritual ficou evidenciado neste estudo em base bibliográfica. A empatia ajuda o próprio conselheiro a se conhecer, ao se permitir compreender a história do outro mediante uma escuta atenta. Ao se dar conta de suas próprias forças e fraquezas, o conselheiro, ao experimentar a graça da cura divina em suas próprias feridas, tornar-se-á o ferido que cura. Multiplica desse modo o amor e a graça de Jesus em favor de outras pessoas.

Palavras-chaves: Empatia. Cuidado espiritual. Cuidado pastoral. Aconselhamento.

\begin{abstract}
:
One of the fundamental elements for listening to and welcoming people who seek pastoral counseling and need spiritual care is empathy. The purpose of this study is to describe, from Edith Stein's studies, the nature of empathy and reflect on its importance in spiritual care. The value of an empathic attitude on the part of the spiritual counselor was evidenced in this study on a bibliographic basis. Empathy helps the counselor to know himself by allowing himself to understand the other's story through attentive listening. Upon realizing his own strengths and weaknesses, the counselor, upon experiencing the grace of divine healing in his own wounds, will become the wounded who heals. In this way, he multiplies the love and grace of Jesus for the sake of others.
\end{abstract}

Keywords: Empathy. Spiritual care. Pastoral care. Counseling.

\footnotetext{
${ }^{1}$ Pós-doutor em Teologia pela PUCPR. Docente da Faculdade Fidelis e da Faculdade de Teologia Evangélica (FATEV). hartmut.august@fidelis.edu.br.

${ }^{2}$ Doutora em Teologia pela PUCPR. Docente da Faculdade Fidelis e da Faculdade de Teologia Evangélica (FATEV). mariluce.august@ fidelis.edu.br.
} 


\section{INTRODUÇÃO}

A atitude empática é um tema desprovido de compreensão no âmbito do aconselhamento pastoral ou, num termo atual mais abrangente, do cuidado espiritual. É possível que em ambientes eclesiais ainda se prefira falar mais do que ouvir o aconselhando, por diversas razões. Entre elas pode estar um sentimento de necessidade de prover, o mais breve possível, uma resposta certeira, de cunho doutrinário ou bíblico, por se considerar mais adequado o aconselhando sair da crise o quanto antes e talvez por se acreditar ser esta a expectativa dele. No entanto, existem outros elementos e formas a serem considerados na dinâmica dos aconselhamentos. Nesse sentido, um dos elementos fundamentais para a escuta e acolhimento das pessoas que buscam aconselhamento é a empatia. O propósito desse estudo é descrever, a partir dos estudos de Edith Stein, a natureza da empatia e refletir sobre sua importância no cuidado espiritual.

As relações interpessoais são marcadas por diferentes vivências. No encontro com os semelhantes, é possível experimentar a ativação de memórias, o brotar de expectativas e o fluir de fantasias. Essas vivências tem em comum o fato de serem geradas a partir do interior da própria pessoa que vivencia essas experiências. Assim, quando alguém se recorda de algo, significa que se recorda de experiências próprias vividas, pois ninguém pode lembrar-se de lembranças próprias de outras pessoas. De igual modo, a expectativa que uma pessoa tem a respeito de que um acontecimento desejado por ela ocorra, nasce de sua própria consciência, que a faz imaginar como esse evento desejado poderia se desenrolar. O mesmo pode ser afirmado com relação à fantasia, por ser alimentada unicamente pela consciência de quem está fantasiando. Portanto, essas vivências que tem origem na própria consciência são classificadas de egológicas, ou seja, nascidas dentro da própria pessoa (STEIN, 1917, p. 6$11)$.

A empatia, por outro lado, é uma vivência de outra natureza. O que diferencia a empatia das vivências anteriormente descritas é sua origem. Enquanto a memória, a expectativa e a fantasia nascem dentro da própria pessoa que vive essas experiências, a empatia nasce a partir da existência de outra pessoa. "Essa outra pessoa, com a qual eu empatizo, é reconhecida como pessoa, alguém semelhante a mim, como sendo portador de uma identidade própria". Esse outro é possuidor de uma individualidade, cuja presença e ação despertam em mim a experiência da empatia (STEIN, 1917, p. 5). Portanto, embora seja eu quem vivencia a empatia, a origem dessa vivência se encontra numa outra pessoa. Assim, Stein descreve a empatia como sendo uma vivência heterocentrada, ou seja, centrada no outro. 
Desse modo, esse estudo desenvolve a temática proposta da empatia, como compreende Edith Stein, e procura aplicá-la ao cuidado espiritual em três tópicos: A natureza da empatia; A empatia como expressão da graça divina; e A empatia no cuidado espiritual.

\section{A NATUREZA DA EMPATIA}

O Dicionário do Aurélio Online descreve a empatia como sendo a "faculdade de perceber de que modo uma pessoa pensa ou sente" (2014). Adicionalmente, o dicionário explica que, através da experiência da empatia, é possível fazer "suposições bastante precisas acerca da maneira como as outras pessoas sentem ou no que pensam.” Na sua origem latina, a palavra empatia vem da junção do prefixo en (dentro), com a palavra pathos (sofrimento). No idioma alemão, é expressa pela palavra Einfühlung. Essa palavra é a junção de ein (sentir para dentro de) in (como se fôssemos um só) ein, com fühlung (sentir). Outra palavra próxima no idioma alemão é Mitfühlen, que significa sentir junto. Assim, percebe-se que empatia é a capacidade de sentir a partir de dentro (STEIN, 1917, p. 14). Na origem de cada uma dessas palavras, evidencia-se a natureza distintiva da empatia, ao reconhecer a existência de um outro que se apresenta diante de mim. Esse alguém é diferente de mim, diante do qual eu suspendo meus juízos, o que me permite captar a vida interior desse meu semelhante (STEIN, 1917, p. 11).

Para exemplificar a natureza da empatia, é possível imaginar uma mulher que vem até um conselheiro e lhe diz que seu marido faleceu. Ele percebe sua dor. Mas o que é de fato percebido pelo conselheiro? Talvez seu rosto esteja pálido e abatido, com a voz inexpressiva e trêmula. Talvez ela consiga colocar sua dor em palavras. Contudo, a empatia não tem o caráter de uma percepção externa, embora tenha algo em comum com ela. Dessa maneira, a empatia parte da compreensão de que alguém está diante de um outro que lhe é dado, o qual é um ser humano como ele. Pela empatia, não importa quem a pessoa perdeu, nem em que circunstâncias a pessoa faleceu. "Minha atenção estará somente concentrada em perceber a dor da mulher, mesmo sabendo que a dor não é minha” (STEIN, 1917, p. 5).

O contrário da empatia é a apatia $a$ (não/negação) e pathos (sentir). Enquanto a empatia é caracterizada pela compreensão e sua identificação com o outro, a apatia se expressa pela indiferença, insensibilidade e inércia em relação ao outro que está diante de mim (DICIONÁRIO AURÉLIO ONLINE, 2014). Há um “eu” anestesiado que não sente mais, que não se importa pela dor nem pela alegria do outro. Assim, a apatia é uma anestesia 
dos sentimentos em favor do outro.

A intencionalidade dinâmica da consciência conduz uma pessoa para o outro e depois retorna para dentro de si. Conhecendo-se a si mesmo, o ser humano é livre ao andar dentro de si ou de permanecer na superfície. Diante da possibilidade de um encontro significativo com outra pessoa, pode-se optar em seguir avante ou em se fechar em suas próprias experiências passadas. Posso permitir, mediante a empatia, que uma experiência originária de "um outro" intencionalmente chegue até minha interioridade na diferença de duas identidades (STEIN, 1917, p. 6). Ou pode-se recuar com medo de conhecer o que acontece dentro de si próprio.

Em nossas vivências, existe algo que repousa como nosso fundamento, que se manifesta como portador de nossa identidade. Stein descreve esse elemento como sendo nossa alma (Seele), a sede do indivíduo. A alma compreende os sentidos, a vontade, a persistência, a paixão com que a pessoa se envolve, seus sentimentos. A pessoa reconhece sua alma como uma unidade coerente, pois essa unidade coerente compõe sua alma à medida que as vivências na qual ela se revela sejam suas próprias vivências, ações nas quais o seu puro "eu" vive (STEIN, 1917, p. 43). Essa alma é a fonte individual diferente do outro, pois cada vida é única, tem um nome próprio, é insubstituível, não havendo outro igual a ela.

As vivências de cada pessoa são experiências psicofísicas e espirituais. São vivências psicofísicas, visto que a empatia se importa com o corpo que fala e, na medida em que o corpo capta o mundo exterior, preenche sua função nesse espaço (STEIN, 1917, p. 47). E são experiências espirituais, não no sentido religioso, mas no reconhecimento de que há uma terceira dimensão que é qualitativamente estrutural, a consciência intencional. Essa dimensão espiritual é exclusiva dos seres humanos. Por essa razão, a identidade de uma pessoa é caracterizada pela somatória indissociável de seu corpo físico e de seu eu. Seu corpo compreende-se como sendo um corpo vivo, um organismo, e seu eu como sendo a consciência da alma. Essa unidade da alma com o corpo vivo se evidencia na manifestação de diferentes eventos pertencentes a ambas as dimensões, tais como sensações e sentimentos mediados entre a alma e o mundo exterior através de processos físicos e mentais (STEIN, 1917, p. 63).

Quando a pessoa utiliza suas próprias experiências como medida de avaliação dos outros, aprisiona-se em seu próprio modo de ser. Nesse caso, os outros se tornam indecifráveis para essa pessoa, ou, o que é pior, essa pessoa os modela à sua própria imagem e falsifica assim a verdade histórica (STEIN, 1917, p. 129). Porém, na medida em que, no encontro com o outro, eu me dou conta de sua humanidade, sentirei que há vida nele semelhante à minha, atribuindo ao outro a consciência de vida e reconhecendo a existência de 
sua interioridade. Assim, a empatia é uma vivência sui generis, reafirmando que a identidade pessoal é sempre relacional. O outro é o ponto de partida para que eu possa me reconhecer como ser humano. É a convivência com o outro que me assegura que eu vivo" (STEIN, 1917, p. 41). Através da empatia, o eu pode compreender o conteúdo do outro e se descentraliza, abrindo espaço para o outro entrar na minha consciência. Portanto, "ouvir empaticamente é ouvir ativamente, exigindo um investimento emocional na outra pessoa e uma relativa abertura para nossos próprios sentimentos" (CLINEBELL, 2007, p. 74,75). Nesse relacionamento mútuo, estabelece-se o sentido de comunidade, onde se depende uns dos outros, se apoiam mutuamente nas dificuldades e se alegram juntos nas conquistas.

As características individuais observadas no outro precisam fazer sentido entre si. Dessa forma, os comportamentos de uma pessoa haverão de apresentar características essencialmente compatíveis ou essencialmente incompatíveis: uma pessoa verdadeiramente compassiva não pode ser vingativa. Um compassivo não pode ser cruel, um sincero não pode ser diplomático, e assim por diante. Então, à medida que se capta, em cada característica de uma pessoa a unidade de seu caráter, obtêm-se uma expectativa para as experiências futuras (STEIN, 1917, p. 98). E assim, compreender uma ação do outro não significa apenas completá-la empaticamente como uma experiência isolada, mas vivenciar essa ação do outro na compreensão de que ela é parte cheia de sentido da estrutura global dessa pessoa (STEIN, 1917, p. 125).

Na medida em que a identidade pessoal de uma pessoa é construída através dos relacionamentos humanos, ela amplia seu autoconhecimento. Pois considerar "meu eu" interior e suas características significa "ver-me da maneira como vejo o outro e como o outro me vê" (STEIN, 1917, p. 99). Portanto, mediante a empatia, é possível alguém reconhecer a humanidade dos outros, ao ver comportamentos que ela própria também poderia ter. É possível, por exemplo, que um outro "me tenha" uma compreensão mais acurada sobre mim do que eu mesmo, me proporcionando pelo encontro maior clareza sobre mim mesmo. $\mathrm{O}$ outro observa que busco por aprovação ao meu redor quando pratico uma boa ação, ao passo que eu penso estar simplesmente agindo por pura misericórdia. $\mathrm{Na}$ medida em que as pessoas se defrontam empaticamente com valores que até então desconheciam, tornam-se conscientes de suas próprias fraquezas, na medida em que cada compreensão de outra pessoa pode representar o ponto de partida de uma comparação de valores. A pessoa tem, assim, a oportunidade de se reconhecer como tendo mais ou menos valor em comparação ao outro (STEIN, 1917, p. 130). Assim, a empatia e a percepção interior trabalham lado a lado para descortinar o interior da pessoa para si mesma (STEIN, 1917, p. 101). 
Através da empatia é possível vivenciar valores e descobrir camadas correlatas de minha pessoa, cuja descoberta minhas próprias vivências ainda não me haviam proporcionado. Quem nunca se defrontou com um perigo eminente, pode, mediante uma atitude empática diante de uma situação vivida pelo outro, reconhecer-se como sendo corajoso ou covarde. Embora a pessoa não tenha vivido pessoalmente a experiência de outra, através da empatia ela pode se imaginar na situação da outra e refletir de que maneira ela agiria se estivesse no seu lugar (STEIN, 1917, p. 129). Por exemplo, a pessoa pode nunca ter sido abandonada por seu cônjuge, mas mediante uma atitude empática diante do relato e dos sentimentos expressos por alguém que está diante dela, pode compreender o que se passa em seu interior. Pode atribuir um valor à maneira como ela reagiu à perda e adquirir assim empaticamente uma compreensão do seu sofrimento, que até então lhe era desconhecido.

Enfim, a empatia é um movimento de profunda identificação de si mesmo com as experiências do outro e com o outro propriamente dito. A natureza da empatia pode ser evidenciada nos relacionamentos humanos significativos com os quais podem ser construídas vivências positivas que dependem do autoconhecimento tanto de suas próprias forças como de suas limitações.

\section{A EMPATIA COMO EXPRESSÃO DA GRAÇA DIVINA}

Cristo é a expressão da empatia por excelência. Cristo é o outro que se perde em favor de alguém, pois o sacrifício da cruz é celebração da empatia divina que se doa a favor dos seres humanos. Conforme 1Pedro 2.24, "Jesus é o enviado de Deus que, mesmo ferido, cura. Por meio de suas feridas somos curados" (NOUWEN, 2000, p. 228). Da mesma forma, Cristo oferece o exemplo perfeito da empatia horizontal, pois em Cristo a pessoa é conduzida a se identificar com a outra, como sendo uma com ela em Cristo (ALES BELLO, 2013, p. 224). Para Clinebell (1987, p. 406), é necessário experimentar consideração positiva incondicional, pois significa "experimentar num relacionamento o equivalente humano da graça. Graça é o amor que não se precisa granjear, porque já existente num relacionamento" (CLINEBELL, 1987, p. 406).

Como bons imitadores de Cristo, existe o desafio de se estender a graça divina às pessoas ao redor, mediante uma atitude empática demonstrada por uma "sensibilidade para com os sentimentos do outro" (FRIESEN, 2004, p. 92). As pessoas são chamadas ao mesmo sacrifício da auto entrega praticado por Jesus Cristo: "Portanto, sejam imitadores de Deus, 
como filhos amados, e vivam em amor, como também Cristo nos amou e se entregou por nós como oferta e sacrifício de aroma agradável a Deus" (Ef 5.1,2). Nesse texto, o apóstolo Paulo desafia os crentes a serem imitadores de Deus e de Cristo, vivendo em amor uns com os outros e exalando um aroma agradável a Deus e dando bom testemunho diante do próximo. Assim, também as próprias feridas de uma pessoa podem ser instrumento de cura na vida das outras.

Do ponto de vista da fenomenologia das religiões, o cristianismo é classificado como a religião do amor (ALES BELLO, 2004, p. 270). Somente como religião que desafia seus seguidores a amar seu próximo, é possível compreender o paradigma proposto por Jesus de que "quem perde a sua vida por minha causa a encontrará" (Mt 10.39b). Esse paradoxo é possível pela empatia, pois o amor ao próximo está ligado à ideia do outro eu, que é destinatário do meu amor. Portanto, "o cristão deve inserir-se na perspectiva segundo a qual a função do espírito, inclusive do seu próprio espírito, é sempre caritativa" (ALES BELLO, 1998, p. 183). Não podemos afirmar que amamos a Deus se ignoramos nosso próximo (1Jo 4.20). 'Empatia no fundo é amor 'ágape'. Amor este que sabe o que se passa com o outro, que se aproxima do outro exclusivamente pelas suas próprias necessidades, sem interesses pessoais e secundários" (FRIESEN, 2004, p. 92).

$\mathrm{Na}$ medida em que alguém se aproxima empaticamente do outro, em especial daquele que sofre, estará agindo como portador da graça divina. Assim, "todos saberão que vocês são meus discípulos, se vocês se amarem uns aos outros" (Jo 13.35). Portanto, a empatia faz parte da natureza graciosa e amorosa de Deus e faz parte da natureza das pessoas. Ela é fundamental para o acolhimento adequado daquele que se aproxima de alguém em busca de ajuda.

\section{A EMPATIA NO CUIDADO ESPIRITUAL}

No cuidado e atendimento a pessoas que sofrem perdas, como por exemplo, de seu cônjuge, a disposição de ouvir de maneira empática é essencial. Depois do adeus do seu cônjuge, seja pela sua morte ou separação, a pessoa enlutada poderá ser ajudada de maneira significativa se o conselheiro ouvir sentimentos e palavras, "incluindo sentimentos que estão nas entrelinhas, que são dolorosos demais para serem expressos com palavras" (CLINEBELL, 1987, p. 72). Nesse momento, os fatos ou julgamentos morais perdem relevância. Caberá ao conselheiro desenvolver uma compreensão empática, entrando "no mundo interior de 
significados e sentimentos profundos da pessoa, escutando com atenção e interesse" (CLINEBELL, 1987, p. 406). Somente dessa maneira, o conselheiro poderá verdadeiramente se aproximar da experiência da pessoa que sofre e compreender sua dor. Apenas ouvindo-a atentamente, a pessoa já estará sendo grandemente ajudada (KEMP, 1999, p. 103). No entanto, "são muitas as pessoas à procura de um ouvido que as ouça. Elas não o encontram entre os cristãos, porque eles falam quando deveriam ouvir. Quando não mais ouve a seu irmão (ou irmã), em breve também não mais ouvirá a Deus" (BONHOEFFER, 1959, p. 97).

No aconselhamento a pessoas é condição que o conselheiro tenha uma auto compreensão equilibrada. Pois "quanto mais soubermos a respeito de nós mesmos, menor a probabilidade de sermos ameaçados" pelas experiências que nos são apresentadas (COLLINS, 2004, p. 32). Além da autocompreensão, pela empatia o conselheiro estará em condições de se encontrar com a outra pessoa como um "ferido que cura" (NOUWEN, 2000, p. 230). Essa atitude "provém de uma consciência vívida de familiaridade com a doença e o pecado, a solidão, alienação e o desespero da pessoa" (CLINEBELL, 1987, p. 407). Pois, "identificar-se com a fundamental humanidade de uma pessoa em desespero ameaça nossas frágeis defesas contra nosso próprio desespero" (CLINEBELL, 1987, p. 407,408). Na identificação com o outro, o conselheiro reconhece que a dor do outro também poderia ser sua, que a fragilidade do outro igualmente poderia ter se manifestado em sua vida. Como sarador ferido, o conselheiro se reconhece como sendo um mendigo que sabe onde encontrar pão, pois já teve fome e foi saciado pelo Senhor Jesus.

Um conselheiro eficaz terá como alvo ajudar a pessoa que sofreu perdas a melhorar a compreensão a respeito de sua individualidade, ampliando assim suas possibilidades de um agir consciente e responsável. O conselheiro não violenta nem atropela esse processo. Pois é absolutamente empático, não induzindo, mas conduzindo. Compreende quem é o outro, considera sua história individual, os seus talentos e qualidades e conduz o processo de autoconhecimento. Desse modo, se busca apresentar ao aconselhando "uma robusta noção da própria identidade como pessoa" (CLINEBELL, 1987, p. 407).

Agindo desse modo, o conselheiro de pessoas que perdem seu cônjuge, por exemplo, conduzirá o aconselhando a uma compreensão de sua própria vida, capacitando-o, cada vez mais, a ser protagonista de sua história depois do adeus do seu parceiro de vida. Esse princípio vale para a maioria das especificidades do cuidado espiritual. 


\section{CONCLUSÃO}

Vive-se num mundo marcado pela competição e pelo egoísmo onde existe pouca escuta eficiente do outro. Esse estilo de vida infiltra-se sorrateiramente nas famílias e comunidades cristãs. Em contraposição a esse contexto, a empatia se caracteriza como sendo uma vivência centrada na outra pessoa e que ocorre consciente e intencionalmente. Sendo uma vivência essencialmente relacional, como afirma Stein (1917, p. 99), a empatia reafirma a identidade pessoal e leva ao autoconhecimento, pois através dela é possível ver como os outros me veem e como eu me vejo iluminado pelas experiências do outro. Assim, num encontro empático, ao mesmo tempo em que o outro nos permite coparticipar de sua vida, ele espera que tomemos sobre nós os seus pesos, para consolá-lo, aconselhá-lo e ajudá-lo. A empatia, pois, é coparticipação na alegria, na dor, no sofrimento do outro.

A empatia, como expressão de auto entrega, caracteriza-se como expressão da graça divina. Pois Cristo doa-se a favor do ser humano na cruz, como maior exemplo de empatia. Agora os seres humanos, como participantes do seu corpo, são chamados a fazer o mesmo, entregando-se a favor do próximo. A empatia permite a experiência de consideração positiva a favor do próximo. Assim, é pela empatia que se pode revelar Cristo e sua graça àqueles com os quais as pessoas convivem, oferecendo compreensão, relacionamentos cheios de significado e crescendo na compreensão que cada um tem de si mesmo.

Olhando para pessoas que sofrem suas mais diversas perdas, é preciso apoiá-las. No aconselhamento, somos chamados a compreender empaticamente suas histórias, sem fazer juízo de valor. Implica em reconhecer que a dor do outro também poderia ser nossa. E conduzir aqueles que sofrem ao autoconhecimento e à crescente autonomia na condução de suas vidas. Somente assim, mediante um agir empático, o processo de luto pelas mais diversas perdas poderá tornar-se menos sofrido, permitindo o desabrochar de uma vida com novos sentidos e novos propósitos, nunca antes vislumbrados.

\section{REFERÊNCIAS}

ALES BELLO, Angela. Fenomenologia e Ciências Humanas: Psicologia, História e Religião. Bauru: EDUSC, 2004.

ALES BELLO, Angela. Culturas e Religiões - Uma leitura fenomenológica. Bauru: EDUSC, 1998.

APATIA. In: Dicionário do Aurélio Online. Disponível em: <http://www.dicionariodo 
aurelio.com. Acesso em: 07/09/2019.

BÍBLIA. Nova Versão Internacional. São Paulo: Vida, 2003.

BONHOEFFER, Dietrich. Life Together. Nova Iorque: Harper \& Brothers, 1959.

CLINEBELL, Howard. Aconselhamento Pastoral. São Leopoldo: Sinodal, 1987.

COLLINS, Gary R. Aconselhamento Cristão - edição século 21. São Paulo: Vida Nova, 2004.

EMPATIA. In: Dicionário do Aurélio Online. Disponível em:

<http://www.dicionariodoaurelio.com>. Acesso em 07/09/2020.

FRIESEN, Albert. Cuidando do Ser. Curitiba: Esperança, 2004.

KEMP, Jaime. Antes de Dizer Adeus. São Paulo: Mundo Cristão, 1999.

NOUWEN, Henri J. M. Pão para o Caminho. São Paulo: Loyola, 1999.

STEIN, Edith. La struttura della persona umana. A cura di Angela Ales Bello. Titolo originale: Der Aufbau der menschlichen Person. Traduzione Italiana di M. D’Ambra. Roma: Città Nuova, 2000.

STEIN, Edith. Zum Problem der Einfühlung. Halle: Buchdruckerei des Waisenhauses, 1917. 